\title{
Effect of extraction solvents on antioxidant and wound healing properties of Carica papaya leaves extract
}

\author{
${ }^{1}$ Soib, H.H., ${ }^{2}$ Ismail, H.F., ${ }^{3, *}$ Ya'akob, H., ${ }^{1}$ Idris, M.K.H. and ${ }^{3}$ Abd Aziz, A. \\ ${ }^{1}$ Department of Bioprocess and Polymer Engineering, School of Chemical and Energy Engineering, Faculty \\ of Engineering, Universiti Teknologi Malaysia, Skudai 81310, Malaysia \\ ${ }^{2}$ Institute of Marine Biotechnology, Universiti Malaysia Terengganu, Kuala Terengganu 21030, Malaysia \\ ${ }^{3}$ Institute of Bioproduct Development, Universiti Teknologi Malaysia, Skudai 81310, Malaysia
}

Article history:

Received: 23 October 2019

Received in revised form: 13 April 2020

Accepted: 27 April 2020

Available Online: 30 April 2020

\section{Keywords:}

Carica papaya,

Extraction solvents,

Antioxidant,

Wound healing,

DPPH

DOI:

https://doi.org/10.26656/fr.2017.4(S2).S03

\begin{abstract}
Carica papaya is a well-known plant that has been reported to exert various pharmacological activities including antioxidant and wound healing properties. However, to date, the lack of scientific evidence has been explored on the efficiency of the solvents towards $C$. papaya extract as a potential wound healer. The selection of proper extraction solvent plays a pivotal role in extracting the bioactive compounds from the plant. Therefore, the present study was aimed to examine the effect of three types of extraction solvents (methanol, ethanol and aqueous) on the antioxidant activity and wound healing potential of $C$. papaya leaves. In this study, the effect of different solvents of $C$. papaya leaves extracts were determined through 1,1-Diphenyl-2-picrylhydrazyl (DPPH) radical scavenging activity, cytotoxicity assay and scratch migration assay on Human Skin Fibroblast cells (HSF1184). The result showed that the methanolic extract of C. papaya possessed a significant antioxidant activity as compared to ethanol and aqueous extract. The result also demonstrated that methanolic extract significantly stimulates the highest migration rate of HSF1184 cell at a concentration of $3.9 \mu \mathrm{g} / \mathrm{mL}, 7.8 \mu \mathrm{g} / \mathrm{mL}$ and $15.6 \mu \mathrm{g} /$ $\mathrm{mL}(p \leq 0.05)$ after $48 \mathrm{hrs}$ with no cytotoxicity observed at the concentration lower than $1000 \mathrm{mg} / \mathrm{mL}$ as compared to other solvents. HPLC analysis of methanol extract identified the presence of two flavonoids (catechin, quercetin) and two phenolic acids (caffeic acid, cinnamic acid). The findings suggest that the methanolic extract of $C$. papaya is effective in fighting free radicals and it has good wound healing activities. It also has the potential to be further explored for its medicinal values owing to the abundance of bioactive compounds from the extract.
\end{abstract}

\section{Introduction}

A proper extraction process of herbal plants for isolation of its bioactive compounds is essential in pharmaceutical, food and cosmetic application. Richard (1998) stated that two important points should be considered during the extraction process; 1) the purpose in conducting the extraction, and 2) the nature of the targeted compound that needs to be isolated. Many contributing factors play a part in a successful extraction procedure, such as part of the plant used, types of solvent, and extraction technique. The selection of a suitable solvent is critical as it greatly affects the active compounds that need to be isolated. "Like dissolves like" is the basic principle in which the solvent polarity influences the solubility of active compounds. If the compound of interest belongs to the polar compound; hence, a polar solvent is the most appropriate choice to use and vice versa. Studies have reported that extracting bioactive compounds using a different type of solvent significantly affect phytochemical content and biological activities (Perumal et al., 2013; Thouri et al., 2017). Moreover, a good solvent should possess a less toxic effect, can preserve the active compound and enhance the extraction yield and its bioactivities.

Carica papaya Linn belongs to the genus Carica and the family of Caricaceae. It is the most cultivated plants in tropical and subtropical countries such as Malaysia, Indonesia, Australia, Brazil, India and China. The young leaves of C. papaya exert the most prominent antioxidant activities and contained the highest total phenolic and 
flavonoid content as compared to other parts of the plant (Maisarah et al., 2013; Gogna et al., 2015; Hadadi et al., 2018). Asghar et al. (2016) reported that the C. papaya leaves have the highest scavenging activity and inhibition of peroxidation as compared to its bark, root and pulp. Additionally, the young leaves of $C$. papaya contained high levels of secondary metabolites including caffeic acid, cinnamic acid, chlorogenic acid, quinic acid, coumaric acid, vanillic acid, protocatechuic acids, naringenin, hesperidin, rutin, and kaempferol as compared to old leaves (Gogna et al., 2015).

Various literature studies have reported on the effect of C. papaya for its wound healing activities (Prashant et al., 2011; Ancheta and Acero, 2015; Nafiu and Rahman, 2015; Ajani and Ogunbiyi, 2015; Nafiu et al., 2016). The wound healing properties have been attributed to its antioxidant, anti-inflammatory and antimicrobial activities (Gosh and Gaba, 2013). Wound healing is a complex and dynamic process involving overlapping interactions among cellular structures, tissue layers, and different types of cells. The wound can be interpreted as a disruption of the functional continuity of cells and tissues due to physical, chemical, microbial infection or immunology process. In general, the wound healing process comprises three distinct phases; inflammation, proliferation and remodeling (Kurahashi and Fujii, 2015). Recently, the current application for wound healing treatment involves autographs, allografts, cultures epithelial autographs and wound dressing (Dreifke et al., 2015). However, distinct types of treatment differ in the category of the wound, such as acute or chronic wounds. Adaptation of patients to the treatment also varies with age, sex, lifestyle, health status, and severity of the wounds (Ghosh and Gaba, 2013).

To date, most of the extract preparations of $C$. papaya for wound healing potential used varieties of solvents from polar to mid polar. Nevertheless, it is difficult to find a relationship of in vitro study based on the effect of different solvent against antioxidant and wound healing activities. Therefore, the present study was aimed to examine the effect of different extraction solvents on antioxidant and wound healing activities of C. papaya leaves extracts.

\section{Materials and methods}

\subsection{Materials}

2, 2-diphenyl-1-picrylhydrazyl. (DPPH), and thiazolyl blue tetrazolium bromide (MTT), catechin, and ascorbic acid were purchased from Sigma-Aldrich ${ }^{\circledR}$, USA. HPLC- grade methanol, ethanol and FolinCiocalteu reagent were purchased from Merck®.
Penicillin streptomycin (PS), Dulbecco's Modified Eagle Medium (DMEM), trypsin EDTA, phosphate-buffered saline (PBS), fetal bovine serum (FBS) were purchased from $\mathrm{GIBCO}^{\circledR}$, USA. The green leave of $C$. papaya cultivar 'Eksotika' was collected from the Malaysian Agriculture Research and Development Institute (MARDI), Serdang, Selangor, Malaysia. The sample was identified and authenticated by botanist Dr. Shamsul Khamis and a voucher specimen (SK 3143/17) was deposited to Herbarium Institute of Bioscience, Universiti Putra Malaysia, Serdang, Selangor, Malaysia.

\subsection{Preparation of the extracts}

The method of extraction was conducted according to Vuong et al. (2013) with slight modification. Initially, the leaves were washed with tap water and dried in the oven for two (2) days at $50^{\circ} \mathrm{C}$. Afterward, the dried leaves were ground using blender (Model: CB15V, Waring Commercial ${ }^{\circledR}$, USA) to obtain a fine powder. $7.5 \mathrm{~g}$ of $C$. papaya leaves powder was subjected to a reflux extraction system for 20 mins $\left(70{ }^{\circ} \mathrm{C}\right)$ using three different solvents; methanol, ethanol, and aqueous (100 $\mathrm{mL})$. Extracts were filtered and concentrated using a rotary vacuum evaporator at $60^{\circ} \mathrm{C}$. The dried extracts were stored at $-20^{\circ} \mathrm{C}$ until further use.

\subsection{DPPH radical scavenging activity}

The scavenging activity of extracts against DPPH radical was performed based on Maisarah et al. (2013) with modifications. $100 \mu \mathrm{L}$ of DPPH solution $(0.1 \mathrm{mM})$ was added into each well plate containing different concentrations of extracts $(0.5,0.25,0.125,0.063,0.031$, $0.016,0.008 \mathrm{mg} / \mathrm{mL})$. The mixture was kept in the dark at room temperature for 30 mins. Ascorbic acid and catechin were used as the reference standard. The absorbance was measured at wavelength $517 \mathrm{~nm}$ whereas the activity of radical scavenging was calculated using the equation:

(\%) Inhibition of DPPH scavenging activity $=\left[\left(\mathrm{A}_{0}-\mathrm{A}_{1}\right) /\right.$ $\left.\mathrm{A}_{0}\right] \times 100$

Where $A_{0}$ is the absorbance of the control and $A_{1}$ is the absorbance of the sample extract or standard.

\subsection{Cell culture maintenance}

Human Skin Fibroblast 1184 cell line (ECACC, United Kingdom) was maintained in DMEM supplemented with $10 \%$ FBS and $1 \%$ PS. The cell was incubated under $5 \% \mathrm{CO}_{2}$ at $37^{\circ} \mathrm{C}$. Cell confluence at $80-$ $90 \%$ was used for seeding and treatment.

\subsection{Cytotoxicity assay}

Cytotoxicity assay was conducted according to 
Ismail et al. (2017) with modifications. Cells at a concentration of $1.0 \times 10^{5}$ cell $/ \mathrm{mL}$ were seeded into 96well plates and incubated overnight. Treatment was initiated by replacing the media with $200 \mu 1$ of various concentrations of extracts ranging from $3.9 \mu \mathrm{g} / \mathrm{mL}$ $1000 \mu \mathrm{g} / \mathrm{mL}$. After $24 \mathrm{hrs}$ of treatment, the MTT solution was added and re-incubated for another 4 hrs. Formazan crystal was dissolved in $100 \mu \mathrm{l}$ of DMSO and measured at $570 \mathrm{~nm}$ using an ELISA reader (Model Erba: Mannheim).

\subsection{Cell migration rate assay}

Cell migration assay was carried out according to Ahmad et al. (2017) with modifications. Before treatment, post-confluent cells were scratched using 200 $\mu \mathrm{L}$ pipette tip and washed with PBS to remove cell debris. Extracts of $3 \mathrm{~mL}(3.9 \mu \mathrm{g} / \mathrm{mL}, 7.8 \mu \mathrm{g} / \mathrm{mL}$ and 15.6 $\mu \mathrm{g} / \mathrm{mL}$ ) were added and incubated for 48 hrs. Cells without treatment were regarded as negative control while ascorbic acid $(5 \mu \mathrm{g} / \mathrm{mL})$ was regarded as a positive control. Images were captured and analyzed using ImageJ analysis software using the following equation.

\section{$(\%)$ Migration rate $=\left[\left(\mathrm{D}_{0}-\mathrm{D}_{24,48}\right) / \mathrm{D}_{0}\right] \times 100$}

Where $\mathrm{D}_{0}$ is the distance between scratch at $0 \mathrm{hr}, \mathrm{D}_{24}$ is the distance of scratch after $24 \mathrm{hrs}$ of treatment and $\mathrm{D}_{48}$ was the distance of scratch after 48 hrs of treatment.

\subsection{Phytochemical quantification by HPLC}

The quantification of phytochemicals present in the active solvent extract was analyzed using a Waters HPLC system (Model 2690; Milford, MA, USA). HPLC protocol was based on the previous study (Wittenauer et al., 2015) with some modifications. Chromatographic separation of compounds was achieved on a reversedphase Luna ${ }^{\circledR C} 18$ column $(100$ x $4.6 \mathrm{~mm}, 5 \mu \mathrm{m}$; Phenomenex, Torrance, CA) operated at $25^{\circ} \mathrm{C}$ at a flow rate of $0.8 \mathrm{~mL} / \mathrm{min}$. The mobile phase consisted of $2 \%$ $(\mathrm{v} / \mathrm{v})$ acetic acid in water [A] and $0.5 \%$ acetic acid in water and acetonitrile $(50: 50, \mathrm{v} / \mathrm{v})[\mathrm{B}]$ using the following gradient program: $0-5 \% \mathrm{~B}$ (35 mins), 5-20\% B (45 mins), $20-100 \% \mathrm{~B}$ (30 mins), 100\% B isocratic (3 mins), $100-0 \%$ B (10 mins). The detection wavelength was set at $280 \mathrm{~nm}$ and UV/Vis spectra were recorded in the range of 200 to $600 \mathrm{~nm}$. The total run time used was 123 mins and the injection volume of each sample was $30 \mu \mathrm{L}$
The stock solutions of samples were prepared by dissolving $1 \mathrm{mg}$ of standards/sample in $1 \mathrm{~mL}$ of methanol. The identification of compounds was confirmed by comparing the retention time of the standard with the sample. The calibration curves of every standard were constructed for quantification, and the compounds were further calculated based on the linearity of calibration curves standard; $\mathrm{Y}=\mathrm{m} x+\mathrm{c}$ in which $x$ is the concentration of the compound while $\mathrm{Y}$ is a peak area (Table 1). The results were expressed as $\mathrm{mg} / \mathrm{g}$ of extract.

\subsection{Statistical analysis}

All data were collected and analyzed by using oneway ANOVA using SPSS software (version 17.0). The significances of the results were determined by Tukey's test and the $* p \leq 0.05, * * p \leq 0.01$ and ${ }^{* * *} p \leq 0.001$ were set as the limit of significant difference. The results were expressed as mean \pm standard deviation (STDEV) or standard error mean (SEM).

\section{Results and discussion}

\subsection{DPPH radical scavenging activity of Carica papaya leaves}

In this study, the leaves extracts of $C$. papaya were examined to identify the most active extract reflecting on antioxidant potential and wound healing activity. Determination of the antioxidant capacity of $C$. papaya leaves extracts on different solvents was carried out using DPPH scavenging assay. DPPH which is a stable free radical and can reduce its color from dark purple to pale yellow by accepting an electron from an antioxidant agent (Boligon et al., 2014). $\mathrm{EC}_{50}$ was defined as an effective concentration to inhibit $50 \%$ of free radical $\mathrm{DPPH}$. The lowest value of $\mathrm{EC}_{50}$ postulates the highest antioxidant capacities. Under normal physiology of the wound healing process, the exposure of reactive oxygen species (ROS) in low level helps to combat the invading microbial. Unfortunately, the imbalance may lead to oxidative stress and even can delay the healing process (Rasik and Shukla, 2000). At this point, antioxidant capacity plays a major role in avoiding cellular damages and stimulating the migration of cells towards the wound area. Figure 1 presents the dose-dependent trends of antioxidant scavenging activity of $C$. papaya leaves

Table 1. Quantitative analysis of compounds from C. papaya leaves extract (mg/g)

\begin{tabular}{lccccc}
\hline \multicolumn{1}{c}{ Compounds } & $\mathrm{R} t(\mathrm{~min})$ & Calibration equation & Quantity $(\mathrm{mg} / \mathrm{g})$ & Class of compounds & $R^{2}$ \\
\hline (1) Catechin & 11.096 & $\mathrm{y}=7595.4 \mathrm{x}+0.6667$ & $4.98 \pm 0.78$ & Flavonoid & 1 \\
(2) Caffeic acid & 14.476 & $\mathrm{y}=59887 \mathrm{x}-604000$ & $10.82 \pm 0.52$ & Phenolic acid & 0.9962 \\
(3) Quercetin & 37.711 & $\mathrm{y}=141986 \mathrm{x}-691660$ & $4.92 \pm 0.41$ & Flavonoid & 0.9768 \\
(4) Cinnamic acid & 38.014 & $\mathrm{y}=89417 \mathrm{x}-1000000$ & $11.28 \pm 1.21$ & Phenolic acid & 0.9872 \\
\hline
\end{tabular}

$\mathrm{R} t$ : Retention time 
extracts. At the highest tested concentration $(0.5 \mathrm{mg} /$ $\mathrm{mL}$ ), methanol extract scavenged $93.57 \%$ of the free radicals, $85.54 \%$ for ethanol and $82.04 \%$ for aqueous extract. The calculated $\mathrm{EC}_{50}$ value conformed the similar trends where methanol extract demonstrated the lowest $\mathrm{EC}_{50}$ value $(0.193 \mathrm{mg} / \mathrm{mL})$ followed by ethanol $(0.249$ $\mathrm{mg} / \mathrm{mL})$ and aqueous $(0.284 \mathrm{mg} / \mathrm{mL})$. Meanwhile, the $\mathrm{EC}_{50}$ value of standards; catechin and ascorbic acid were much lower than the crude extracts with an $\mathrm{EC}_{50}$ value of $0.005 \mathrm{mg} / \mathrm{mL}$ and $0.014 \mathrm{mg} / \mathrm{mL}$, respectively. It has been shown by Asghar et al. (2016) in their study that ethanol and methanol were found to be the best solvent as compared to water, n-butanol, dichloromethane, ethyl acetate, and n-hexane to extract compounds which are responsible to the antioxidant activity. This could be explained by the efficiency of the solvent used during extraction.

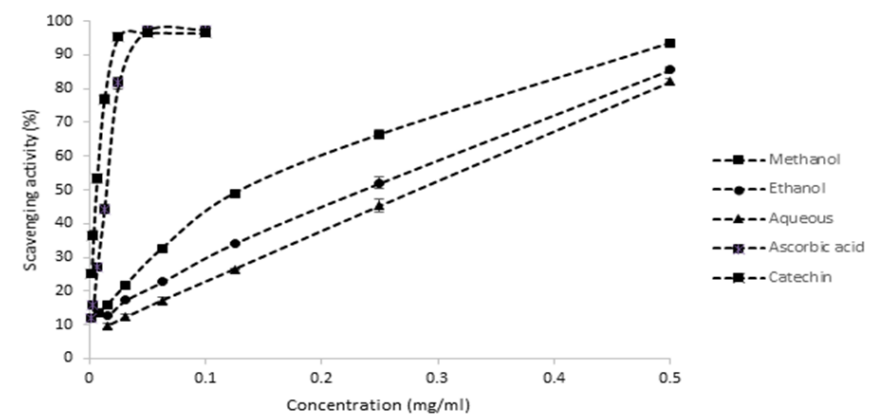

Figure 1. Percentage of scavenging activities of $C$. papaya extracts on DPPH radicals. Results were expressed as the mean of three independent experiments \pm standard deviation. Catechin and ascorbic acid were used as standards
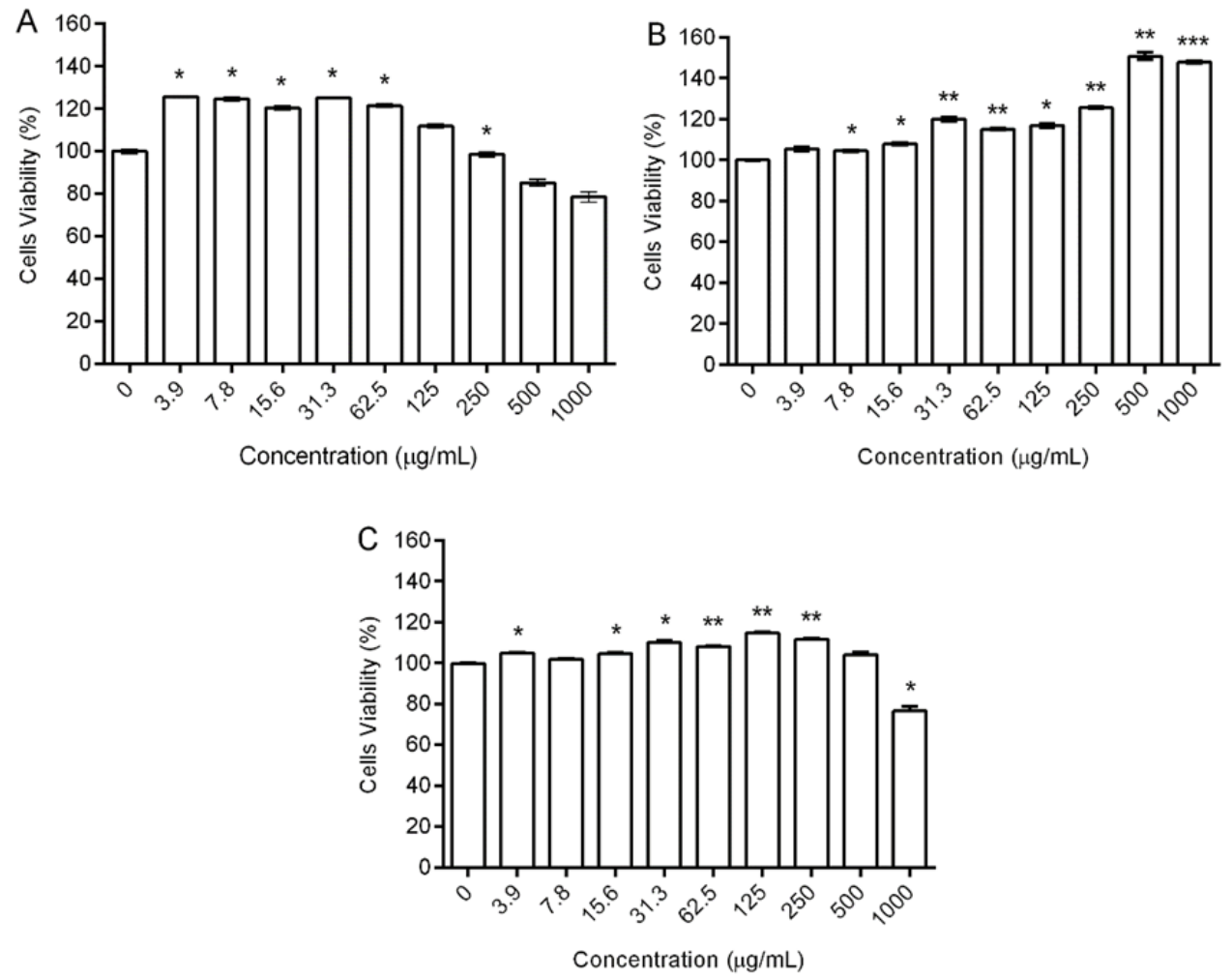

Figure 2. Effect of various concentrations of crude extract of C. papaya leaves extracts from different solvents (A); methanol, (B); aqueous, (C); ethanol on the cell viability of HSF1184 cell line after $24 \mathrm{hrs}$ treatment. Results were expressed as the mean of three independent experiments. ${ }^{*} \mathrm{p} \leq 0.05,{ }^{* *} \mathrm{p} \leq 0.01$ and ${ }^{* * *} \mathrm{p} \leq 0.001$ compared to negative control. 
3.3 Effect of Carica papaya leaves extract on wound scratch assay

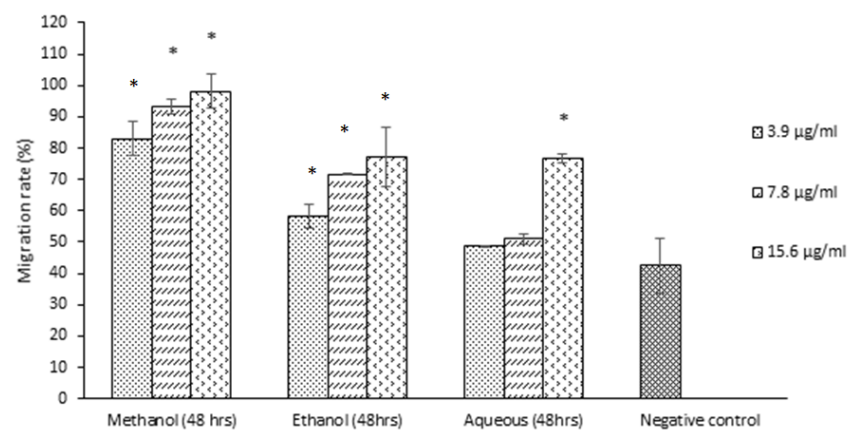

Figure 3. Effect of various concentrations of C. papaya (3.9, $7.8,15.6 \mu \mathrm{g} / \mathrm{mL}$ ) extracts of different solvents on migration rate in HSF1184 cell. The migration rate was analyzed by using Image-J software. Results were expressed as mean $\pm \mathrm{SEM}$ of three independent experiments. ' $*$ ' indicates significant differences $(p \leq 0.05)$ as compared to the negative control.
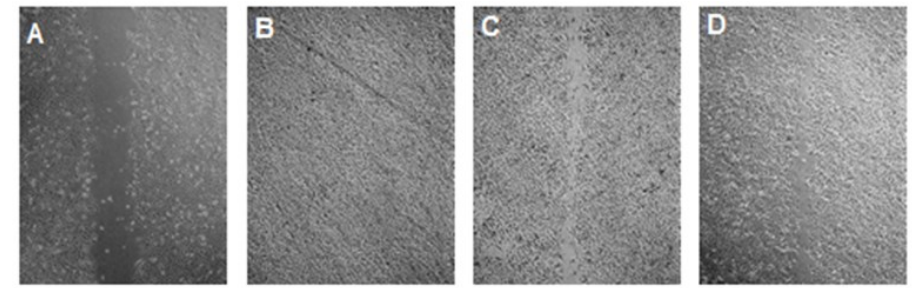

Figure 4. Digital image (x5 magnification) showing the effects of $15.6 \mu \mathrm{g} / \mathrm{mL}$ of $C$. papaya extracts obtained from different solvents (A); Control, (B); Methanol, (C); Aqueous and (D); Ethanol on the migration of HSF1184 cell line in wound scratch assay. The result shows that the scratch area was completely closed when cells treated with methanol extract at $15.6 \mu \mathrm{g} / \mathrm{mL}$.

The cells migration assay was conducted to discover the effect of $C$. papaya extracts on the migration of HSF1184. During the study, a single scratch line was made on the cell to mimic the wound area. The migration of the fibroblast cells to fill the scratched area indicates the features of wound healing. The effect of C. papaya extracts of different solvents on the cell migration rate in HSF1184 cells was shown in Figure 3 and Figure 4. The non-cytotoxic concentrations of $3.9 \mu \mathrm{g} / \mathrm{mL}, 7.28 \mu \mathrm{g} / \mathrm{mL}$ and $15.6 \mu \mathrm{g} / \mathrm{mL}$ were used based on the previous result of MTT assay. The highest cells migration rate was observed when the cells were treated with methanol extract of $C$. papaya leaves at all concentrations used ( $p$ $\leq 0.05$ ) followed by ethanol and aqueous extract. A rapid migration rate was found at the highest concentration for all extracts $(15.6 \mu \mathrm{g} / \mathrm{mL})$ as compared to the scratch area treated with negative control (without treatment) as illustrated in Figure 4. The result was consistent with antioxidant activity indicating that the methanolic extract possesses the highest activities compared to other extracts. These findings were supported by other studies that revealed the relationship between antioxidants and wound healing processes (Agar et al., 2015; Yuslianti et al., 2015). It is believed that the highest antioxidant capacity may reduce the amount of free radical at the wound area.

\subsection{HPLC analysis of active solvent of Carica papaya extract}

It has been previously confirmed that the methanolic extract of $C$. papaya possessed the most potent antioxidant activities and promoted the fastest migration rate against HSF1184 cells as compared to other extracts. Therefore, further analysis was carried out for the quantitative detection of compounds present in the methanolic extract using the HPLC. The phytochemical analysis identified the presence of two flavonoids compounds (catechin, quercetin) and two phenolic acid compounds (caffeic acid, cinnamic acid) in the methanol extract of C. papaya (Figure 5). Cinnamic acid (11.28 $\mathrm{mg} / \mathrm{g}$ ) was found to be the highest compound in the extract followed by caffeic acid $(10.82 \mathrm{mg} / \mathrm{g})$, catechin $(4.98 \mathrm{mg} / \mathrm{g})$ and quercetin $(4.92 \mathrm{mg} / \mathrm{g})$. The HPLC result was in line with the result reported by other studies whereby they also have successfully identified many compounds from $C$. papaya including catechin, caffeic acid, quercetin and cinnamic acid (Canini et al., 2007; Gogna et al., 2015; Nguyen et al., 2016; Nugroho et al., 2017).

A study conducted by Pitz et al. (2016) showed that the activity of wound healing of Jaboticaba fruit peel hydroalcoholic extract was promoted by its phenolic compounds. The phenolic compounds have protective effects as a result of its antioxidant activity. It also has been supported by Lodhi and Singhai (2013) that luteolin at $0.5 \%$ proved to exert wound healing by antioxidant capacity. Moreover, the phenolic compound also has been evaluated for the synthesis of collagen (Dzialo et al., 2016). Catechin has been abundantly found harbored in the tea plant called Camellia sinensis. A study reported that catechin promotes angiogenesis and upregulate nitric oxide synthase and cyclooxygenase which responsible during the process of anti-inflammatory response (Kapoor et al., 2004). As the persistence of inflammation can delay the healing process, thus the action against wound healing activities takes place. Quercetin is a powerful antioxidant. It has been proved that quercetin exerts various pharmacological effects such as wound healing, anti-inflammatory, anti-cancer, antibacterial, neurodegenerative disease and others (Anand et al., 2016). Isolated quercetin from Salvia leucantha has significantly reduced wound area and promoted epithelisation on albino rats (Rajamanickam et al., 2013). A report by Song et al. (2017) showed that the presence of caffeic acid and cinnamic acid in the extract of Bletilla striata promotes the action of wound healing 
and antioxidant activities. Besides, caffeic acid also has been identified in the active fraction of Prosopis cineraria that exhibited wound healing activities attributed by antioxidant and anti-inflammatory action (Yadav et al., 2018).
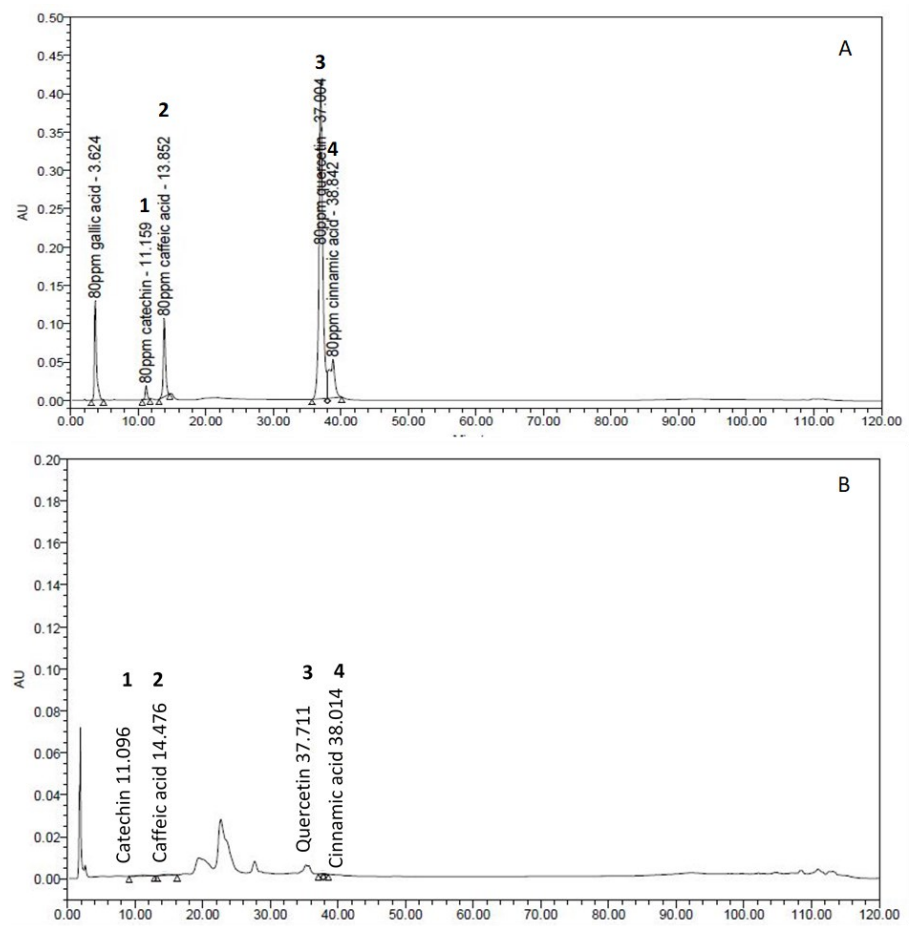

Figure 5. HPLC chromatogram detected from methanolic extract of C. papaya (B) compared with standards (A) at wavelength $280 \mathrm{~nm}$. Peak assignment: (1); Catechin, (2); Caffeic acid, (3); Quercetin, (4); Cinnamic acid.

\section{Conclusion}

Our study demonstrated that the methanolic extract of $C$. papaya was effective in enhancing cells proliferation and cells migration as well as antioxidant activities on HSF1184 cells with no cytotoxicity observed upon treatment. The bioactive compounds present in the active extract have been successfully identified and confirmed by comparing the retention time of the sample with the standards using HPLC analysis. The results provide a basic consideration for further exploration on the isolation of compounds associated with the wound healing process and thereby promote a novel understanding of the mechanism involved.

\section{Conflict of interest}

The authors declare no conflict of interest.

\section{Acknowledgment}

This research work was supported by the Ministry of Education and Universiti Teknologi Malaysia for the grant scheme obtained on 2017 to 2019 under High Center of Excellence [Vote number: R.J130000.7846.4J261].

\section{References}

Afzan, A., Abdullah, N.R., Halim, S.Z., Rashid, B.A., Raja Semail, R.H., Abdullah, N., Jantan, I., Muhammad, H. and Ismail, Z. (2012). Repeated dose 28 - days oral toxicity study of Carica papaya L. leaf extract in Sprague Dawley rats. Molecules, 17 (2012), 4326-4342. https://doi.org/10.3390/ molecules 17044326

Agar, O.T., Dikmen, M., Ozturk, N., Yilmaz, M.A., Temel, H. and Turkmenoglu, F.P. (2015). Comparative Studies on Phenolic Composition, Antioxidant, Wound Healing and Cytotoxic Activities of Selected Achillea L. Species Growing in Turkey. Molecules, 20(10), 17976-18000. https:// doi.org/10.3390/molecules201017976

Ahmad, Z., Sarmidi, M.R. and Hasham, R. (2017). Evaluation of wound closure activity of Cocos nuciferaoil on scratched monolayer of human dermal fibroblasts. Chemical Engineering Transactions, 56, 1657-1662.

Ajani, R.S. and Ogunbiyi, K.I. (2015). Carica papaya Latex Accelerates Wound Healing in Diabetic Wistar Rats. European Journal of Medicinal Plants, 9(3), 1-12. https://doi.org/10.9734/ EJMP/2015/17758

Anand D.A.V., Arulmoli, R. and Parasuraman, S. (2016). Overviews of Biological Importance of Quercetin: A Bioactive Flavonoid. Pharmacognosy reviews, 10 (20), 84-89. https://doi.org/10.4103/09737847.194044

Ancheta, M. and Acero, L. (2015). Wound Healing Property of Carica papaya Stem in Albino Rats. International Journal of Bioscience, Biochemistry and Bioinformatics. 2(6), 68-74. https:// doi.org/10.17706/ijbbb.2016.6.2.68-74

Asghar, N., Naqvi, S.A., Hussain, Z., Rasool, N., Khan, Z.A., Shahzad, S.A., Sherazi, T.A, Janjua, M.R., Nagra, S.A., Zia-Ul-Haq, M. and Jaafar, H.Z. (2016). Compositional difference in antioxidant and antibacterial activity of all parts of the Carica papaya using different solvents. Chemistry Central Journal, 10(5), 1-11. https://doi.org/10.1186/s13065016-0149-0

Canini, A., Alesiani, D., D'Arcangelo, G. and Tagliatesta, P. (2007). Gas chromatography mass spectrometry analysis of phenolic compounds from Carica papaya L. leaf. Journal of Food Composition and Analysis, 20(7), 584-590. https:// doi.org/10.1016/j.jfca.2007.03.009

Dzialo, M., Mierziak, J., Korzun, U., Preisner, M., Szopa, J. and Kulma, A. (2016). The potential of 
plant phenolics in prevention and therapy of skin disorders. International Journal of Molecular Sciences, 17(160), 1-41. https://doi.org/10.3390/ ijms 17020160

Dreifke, M.B., Jayasuriya, A.A. and Jayasuriya, A.C. (2015). Current wound healing procedures and potential care. Materials Science and Engineering. C, Materials for Biological Applications, 48, 651662. https://doi.org/10.1016/j.msec.2014.12.068

Gogna, N., Hamid, N. and Dorai, K. (2015). Metabolomic profiling of the phytomedicinal constituents of Carica papaya L. leaves and seeds by ${ }^{1} \mathrm{H}$ NMR spectroscopy and multivariate statistical analysis. Journal of Pharmaceutical and Biomedical Analysis, 115 (2015), 74-85. https:// doi.org/10.1016/j.jpba.2015.06.035

Gosh, P.K. and Gaba, A. (2013). Phyto-Extracts in Wound Healing. Journal of Pharmacy and Pharmaceutical Sciences, 16(5), 760-820. https:// doi.org/10.18433/J3831V

Hadadi, S.A., Li, H., Rafie, R., Kaseloo, P., Witiak, S.M. and Siddiqui, R.A. (2018). Anti-oxidation properties of leaves, skin, pulp, and seeds extracts from green papaya and their anti-cancer activities in breast cancer cells. Journal of Cancer Metastasis and Treatment, 4(25), 1-15. https:// doi.org/10.20517/2394-4722.2018.22

Ismail, H.F., Hashim, Z., Soon, W.T., Rahman, N.S.A., Zainudin, A.N. and Majid, F.A. (2017). Comparative study of herbal plants on the phenolic and flavonoid content, antioxidant activities and toxicity on cells and zebrafish embryo. Journal of Traditional and Complementary Medicine, 7(4), 452-465. https:// doi.org/10.1016/j.jtcme.2016.12.006

Kapoor, M., Howard, R., Hall, I. and Appleton, I. (2004). Effects of Epicatechin Gallate on Wound Healing and Scar Formation in a Full Thickness Incisional Wound Healing Model in Rats. American Journal of Pathology, 165(1), 299-307. https://doi.org/10.1016/ S0002-9440(10)63297-X

Kurahashi, T. and Fujii, J. (2015). Roles of Antioxidative Enzymes in Wound Healing. Journal of developmental biology, 3(2015), 57-70. https:// doi.org/10.3390/jdb3020057

Lodhi, S. and Singhai, A.K. (2013). Wound healing effect of flavonoid rich fraction and luteolin isolated from Martynia annua Linn. on streptozotocin induced diabetic rats. Asian Pacific Journal of Tropical Medicine, 2013, 253-259. https:// doi.org/10.1016/S1995-7645(13)60053-X

Maisarah, A.M., Nurul Amira, B., Asmah, R. and Fauziah O. (2013). Antioxidant analysis of different parts of Carica papaya. International Food Research Journal, 20(3), 1043-1048.

Nafiu, A.B., Abdulaziz, E. and Rahman, M.T. (2016). Carica papaya juice enhanced in-vitro cell proliferation better than freeze-dried PBS extract using scratch assay. The tropical Journal and Health Science, 2(23), 18-22.

Nafiu, A.B. and Rahman, M.T. (2015). Selenium added unripe Carica papaya pulp extracts enhance wound repair through TGF- $\beta 1$ and VEGF-a signalling pathway. BMC Complementary and Alternative Medicine, 15, 369. https://doi.org/10.1186/s12906015-0900-4

Nguyen, T.T., Parat, M., Hodson, M.P., Pan, J., Shaw, P.N. and Hewavitharana, A.K. (2016). Chemical characterization and in vitro cytotoxicity on squamous cell carcinoma cells of Carica papaya leaf extracts. Toxins, 8(7), 1-11. https://doi.org/10.3390/ toxins 8010007

Nugroho, A., Heryani, H., Choi, J.S. and Park, H. (2017). Identification and quantification of flavonoids in Carica papaya leaf and peroxynitritescavenging activity. Asian Pacific Journal of Tropical Biomedicine, 7(3), 208-213. https:// doi.org/10.1016/j.apjtb.2016.12.009

Perumal, S., Mahmud, R., Piaru, S.P., Lee, W.C. and Ramanathan, S. (2013). Antiradical and Cytotoxic Activities of Varying Polarity Extracts of the Aerial Part of Euphorbia hirta L. Journal of Chemistry, 2013, 983253. https://doi.org/10.1155/2013/983253

Pitz, H.D.S., Pereira, A., Blasius, M.B., Voytena, A.P.L., Affonso, R.C.L., Fenan, S., Trevisan, A.C.D., Ribeiro-do-Valle, R.M. and Mraschin, M. (2016). In vitro evaluation of the antioxidant activity and wound healing properties of Jaboticaba (Plinia peruviana) fruit peel hydroalcoholic extract. Oxidative Medicine and Cellular Longevity, 2016, 3403586. https://doi.org/10.1155/2016/3403586

Prashant, T., Kuldeep, K., Rajnikant, P., Alok, P., Ashish, P. and Pratap, K.S. (2011). Evaluation of aqueous extract of Roots of Carica papaya on wound healing activity in albino Rats. Journal of Chemical and Pharmaceutical Research, 3(4), 291295.

Rajamanickam, M., Kalaivanan, P. and Sivagnanam, I. (2013). Antibacterial and wound healing activities of quercetin-3-O-A-L-rhamnopyranosyl- $(1 \rightarrow 6)-\beta$-Dglucopyranoside isolated from Salvia leucantha. International Journal of Pharmaceutical Sciences Review and Research, 22(1), 264-268.

Rasik, A.M. and Shukla, A. (2000). Antioxidant status in delayed healing type of wounds. International 
Journal of Experimental Pathology, 81(4), 257-263.

https://doi.org/10.1046/j.1365-2613.2000.00158.x

Song, Q., Gou, Q., Xie, Y., Zhang, Z. and Fu, C. (2017). Periplaneta Americana Extracts Promote Skin Wound Healing via Nuclear Factor Kappa B Canonical Pathway and Extracellular SignalRegulated Kinase Signaling. Evidence-Based Complementary Alternative Medicine, 2017, 5821706. https://doi.org/10.1155/2017/5821706

Thouri, A., Chahdoura, H., El Arem, A., Omri Hichri, A., Ben Hassin, R. and Achour, L. (2017). Effect of solvents extraction on phytochemical components and biological activities of Tunisian date seeds (var. Korkobbi and Arechti). BMC complementary and alternative medicine, 17(248), 1-10. https:// doi.org/10.1186/s12906-017-1751-y

Vuong, Q.V., Hirun, S., Roach, P.D., Bowyer, M.C., Phillips, P.A. and Scarlett, C.J. (2013). Effect of extraction conditions on total phenolic compounds and antioxidant activities of Carica papaya leaf aqueous extracts. Journal of Herbal Medicine, 3(3), 104-111. https://doi.org/10.1016/ j.hermed.2013.04.004

Wittenauer, J., Mackle, S., Sußmann, D., SchweiggertWeisz, U. and Carle, R. (2015). Inhibitory effects of polyphenols from grape pomace extract on collagenase and elastase activity. Fitoterapia, 101 (2015), 179-187. https://doi.org/10.1016/ j.fitote.2015.01.005

Yadav, E., Singh, D., Yadav, P. and Verma, A. (2018). Antioxidant and anti-inflammatory properties of Prosopis cineraria based phenolic rich ointment in wound healing. Biomedicine and Pharmacotherapy, 108(2018), 1572-1583. https://doi.org/10.1016/ j.biopha.2018.09.180

Yuslianti, E.R., Bachtiar, B.M., Suniarti, D.F. and Sutjiatmo, A.B. (2015). Antioxidant Activity of Rambutan Honey: The Free RadicalScavenging Activity in vitro and Lipid Peroxidation Inhibition of Oral Mucosa Wound Tissue in vivo. Research Journal of Medicinal Plant, 9(6), 284-292. https:// doi.org/10.3923/rjmp.2015.284.292 